This article was downloaded by: [Lancaster University Library]

On: 30 January 2013, At: 07:14

Publisher: Routledge

Informa Ltd Registered in England and Wales Registered Number: 1072954 Registered

office: Mortimer House, 37-41 Mortimer Street, London W1T 3J H, UK

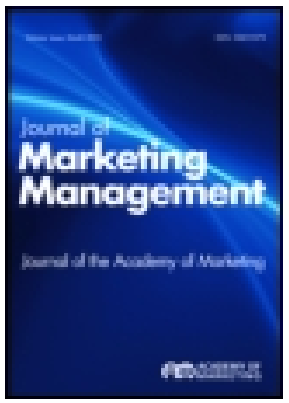

\author{
J ournal of Marketing Management \\ Publication details, including instructions for authors and \\ subscription information: \\ http:// www.tandfonline.com/loi/ rjmm20
}

\title{
The interrelationship between desired and undesired selves and consumption: The case of Greek female consumers' experiences
}

\author{
Katerina Karanika ${ }^{a} \&$ Margaret K. Hogg ${ }^{b}$ \\ a University of Exeter Business School, UK \\ b Lancaster University Management School, UK \\ Version of record first published: 06 Oct 2010.
}

To cite this article: Katerina Karanika \& Margaret K. Hogg (2010): The interrelationship between desired and undesired selves and consumption: The case of Greek female consumers' experiences, J ournal of Marketing Management, 26:11-12, 1091-1111

To link to this article: http:// dx.doi.org/ 10.1080/ 0267257X. 2010.508979

\section{PLEASE SCROLL DOWN FOR ARTICLE}

Full terms and conditions of use: http://www.tandfonline.com/page/terms-andconditions

This article may be used for research, teaching, and private study purposes. Any substantial or systematic reproduction, redistribution, reselling, Ioan, sub-licensing, systematic supply, or distribution in any form to anyone is expressly forbidden.

The publisher does not give any warranty express or implied or make any representation that the contents will be complete or accurate or up to date. The accuracy of any instructions, formulae, and drug doses should be independently verified with primary sources. The publisher shall not be liable for any loss, actions, claims, proceedings, demand, or costs or damages whatsoever or howsoever caused arising directly or indirectly in connection with or arising out of the use of this material. 


\title{
The interrelationship between desired and undesired selves and consumption: The case of Greek female consumers' experiences
}

\author{
Katerina Karanika, University of Exeter Business School, UK \\ Margaret K. Hogg, Lancaster University Management School, UK
}

\begin{abstract}
Earlier work on identity, self, and consumption identified that desired and undesired selves play a significant role in the important global phenomenon of symbolic consumption, but neglected to investigate and conceptualise the interrelationship between desired and undesired selves and consumption. Phenomenological interviews with Greek women are used to elicit consumption experiences linked to positive and negative aspects of the self. The interrelationships between desired and undesired selves in consumption were characterised by two patterns (first, conflicting, and second, compatible desired and undesired selves) that could be linked to consumers' different strategies. Examining these strategies, we extend previous work on the strategies that consumers use to handle identity issues. Finally, we evaluate this theory building derived from the Greek empirical data within the context of US-generated theory about individuals' ways of dealing with self-coherence issues through symbolic consumption; we identify consumers' sense of baffled self and ambivalence in the emotions surrounding consumption.
\end{abstract}

Keywords self; identity; symbolic consumption; possessions; phenomenology

\section{Background}

Previous consumer research has identified that desired and undesired selves play a significant role in the important global phenomenon of symbolic consumption (e.g. Ahuvia, 2005). However, no attempt had been made to investigate and conceptualise the interplay between desired and undesired selves in consumption, and this paper addresses this important gap. The strategies consumers used in order to handle the interrelationships between their desired and undesired selves are examined, extending Ahuvia's theory on the strategies consumers use in handling identity issues. We note differences and similarities between Ahuvia's and our findings, and we identify the different conditions under which consumers follow different strategies. Finally, the theory building derived from this study's Greek empirical data is evaluated within the context of US-generated theory about how consumers, dealing with difficulties in creating a coherent sense of self, negotiate 
conflicting identities through symbolic consumption (e.g. Ahuvia, 2005; Cushman, 1990; Firat \& Venkatesh, 1995). This study identifies, first, consumers' sense of baffled self, and second, more ambivalence in consumers' emotions surrounding consumption than previous studies suggest, contributing to the debates about homogeneity-heterogeneity in global consumer culture.

\section{Consumer culture}

With the erosion of traditional forms of identity, individuals are increasingly obliged to choose and construct their own self-identity from an abundance of competing frameworks of meaning, and they do so partly through consumption (Bauman, 1991; Gergen, 1991; Giddens, 1991; Taylor, 1989). How individuals choose, construct, and communicate their identities through consumption has emerged as a central concern of consumer research (Arnould \& Thompson, 2005; Belk, 1988; Dittmar, 1991; Elliott \& Wattanasuwan, 1998; Holt, 2002; Richins, 1994a, 1994b; Wallendorf \& Arnould, 1988).

Belk (1988) provided the foundations of this research on symbolic consumption. He used the terms 'self', 'sense of self', and 'identity' interchangeably for how a person subjectively perceives who s/he is, and Belk discussed the use of possessions for defining, extending, and strengthening the self, as well as for communicating meaning about the self to the individual and to others. Based on these assumptions, valued possessions emerged as associated with differentiation of the self from others, integration of the self with others, self-continuity, self-change, and more recently with self-coherence (e.g. Ahuvia, 2005; Belk, 1988; Csíkszentmihályi \& Rochberg-Halton, 1981; Kleine, Kleine, \& Allen, 1995; Myers, 1985; Schultz, Kleine, \& Kernan, 1989; Wallendorf \& Arnould, 1988).

\section{Desired and undesired selves and consumption}

The notions of the desired and undesired self, which are imagined selves (Markus \& Nurius, 1986) - that can be positive or negative - within identity projects, have attracted growing interest in consumer behaviour. The work on symbolic consumption in consumer behaviour confirms the role of products and services in portraying a desired self-concept (Belk, 1988; Levy, 1959; Solomon, 1983; Wright, Claiborne, \& Sirgy, 1992) and the role of consumption avoidance in avoiding an undesired self-concept (Banister \& Hogg, 2001, 2003; Freitas, Davis, \& Kim, 1997; Wilk, 1997). The role of products and services both in approaching desired possible selves and in avoiding undesired possible selves has also been explored (Ahuvia, 2005; Patrick \& MacInnis, 2002; Schouten, 1991). However, the dynamics between positive and negative selves in consumption have been neglected in studies of identity projects, even though desired and undesired selves play a significant role in symbolic consumption. We use the word dynamics to signify the way the desired and undesired self interact.

\section{Consumers' sense of self-coherence}

Due to the contemporary difficulties in establishing self-coherence (the erosion of traditional forms of identity and the abundance of competing frameworks of meaning; e.g. Gergen, 1991; Giddens, 1991), consumers' identity projects often involve identity conflicts (e.g. Ahuvia, 2005; Arnould \& Thompson, 2005; Cherrier \& Murray, 2007; Fournier, 1998; Holt \& Thompson, 2004; Murray, 2002; Thompson, 1996; 
Thompson \& Haytko, 1997; Thompson, Locander, \& Pollio, 1990). Ahuvia discussed strategies that consumers in his US study used in coping with their identity conflicts related to symbolic consumption, but he neglected the conditions under which consumers follow different strategies. Moreover, since self-concept and consumption are developed within a sociocultural context, consumers in other cultures may deal differently with issues of identity and consumption.

Three discourses refer to the difficulties in establishing self-coherence: fragmented multiple selves, the empty self, and the coherent sense of self created out of synthesis of opposite identities.

Firat and Venkatesh (1995) propose that the contemporary consumer possesses fragmented multiple selves and has no need to reconcile identity contradictions; s/he is not strongly committed to identities, chooses identities (from a wide range) based on his/her momentary wants, and then discards these identities without feeling anxiety or uncertainty but rather enjoying the freedom from needing a centred, authentic self.

In contrast, Cushman (1990) argues that the contemporary consumer desires a unified and coherent identity that is difficult to construct due to the abundance of competing lifestyles and subcultures that lack shared meaning. In this view, the consumer develops feelings of self-doubt and unworthiness, and a sense of an 'emptyself', and engages in an ongoing lifestyle of consumption but never reaches fulfilment.

In the middle of these two opposing views lies the work of Gould and Lerman (1998), Thompson and Hirschman (1995), Murray (2002), Schau and Gilly (2003), and Ahuvia (2005) who explored the use of consumption to construct a coherent identity within a fragmented society. Consumers in these studies wanted a coherent identity narrative but experienced difficulties in establishing a coherent sense of self and yet did not necessarily experience an 'empty-self'. Rather, consumers were shown often to create a coherent self-narrative out of potentially disjointed material, synthesising opposite identities through consumption (Ahuvia, 2005) and flexibly incorporating dualism.

\section{Identity narratives}

Narratives are considered a fundamental way by which the consumer structures and therefore makes sense of his/her identity, life, and consumption experiences (Ahuvia, 2005; Fournier, 1998; Giddens, 1991; Shankar, Elliott, \& Goulding, 2001; Thompson, 1997; Thompson \& Tambyah, 1999). Narrative theory places emphasis on the narrative structure and works on the premise that, although the narratological constructions may be marked by internal contradictions and compartmentalised beliefs, narratives nonetheless enable people to construct a sense of continuity and coherence from the flow of their life experiences (Gergen, 1991; Giddens, 1991; Thompson, 1997). This structurally oriented approach focuses on how a person frames meanings, personal concerns, and life goals in order to derive a coherent sense of personal history (Thompson, 1997). The narrative approach suggests that a coherent self-narrative represents a coherent sense of self (e.g. Ahuvia, 2005).

However, according to McAdams (2006, p. 118), 'Life is messier and more complex than the stories we tell about it'. In a similar way, Sartre maintained that the stories we tell do not need to relate easily to the lives we live; narrative coherence may signify 'bad faith'. And according to Raggatt (2006), life stories should strive to portray the rich diversity of lived experience resisting dominant cultural narratives. Therefore, calls have been made (Gubrium \& Holstein, 1998; McAdams, 2006) for a focus on both the coherence and the incoherence (diversity, contrasting trends) of narratives. 
McAdams (2006) maintains that a large problem in evaluating life narratives is that the coherence in a story may not reflect a respondent's own 'lived experience'.

\section{The phenomenological self}

Because a coherent self-narrative (e.g. Ahuvia, 2005) may not necessarily represent the experience of a coherent sense of self, we draw on the phenomenological approach to the self (Reed, 2002; Thompson, Pollio, \& Locander, 1989) that shares similarities with the narrative analysis (e.g. they both draw heavily on hermeneutics) but primarily focuses on the experience of self and consumption rather than the structure of these experiences (see Table 1). The self is seen as an ongoing project, a construction, recreated each moment through choices from different meanings after dialogue with different images of the self from past and future, mediated by anticipated responses of significant or generalised others (Heidegger, 1962; Sartre, 1943).

\section{Sociocultural context}

Consumer culture theorists study consumers in consumption contexts (Arnould \& Thompson, 2005). Consumers' identity projects in Mediterranean and non-American cultures such as Greece have been relatively neglected. This exploratory study into how Greeks pursue meaning and identities through consumption could therefore add to existing consumer research, which hitherto has concentrated largely on symbolic consumption in the United States, extending our understanding of the role of consumption in identity projects (Arnould \& Thompson, 2005), and potentially providing a more nuanced understanding of how symbolic consumption works within global consumer culture.

\section{Self-object relationship}

The relationship between the self and the objects often remains under-theorised (Borgerson, 2005) in consumer studies. Belk (1989, p. 130) emphasised the subject's agency (but also acknowledged a kind of agency on the part of objects) in merging identity with objects. D. Miller (1987) emphasised objects as active in subject formation. This study adopts the constructionism view on meaning (Crotty, 2003) that bridges the previous two views, emphasising the co-creation of subject and object by stating that meaning is constructed and comes out of the interplay between object and subject.

Table 1 Narrative approach vs. Phenomenology

\begin{tabular}{llll}
\hline & \multicolumn{1}{c}{ Assumptions } & \multicolumn{1}{c}{ Focus } & \multicolumn{1}{c}{ Result } \\
\hline $\begin{array}{l}\text { Narrative } \\
\text { approach }\end{array}$ & $\begin{array}{l}\text { (Coherent) } \\
\text { self-narrative } \\
\text { represents } \\
\text { (coherent) sense } \\
\text { of self }\end{array}$ & $\begin{array}{l}\text { How people frame } \\
\text { meanings to derive a } \\
\text { coherent sense of } \\
\text { personal history despite } \\
\text { internal contradictions }\end{array}$ & $\begin{array}{c}\text { Synthesis of potential } \\
\text { contradictions }\end{array}$ \\
$\begin{array}{c}\text { Phenomenology } \\
\text { Sense of self } \\
\text { inferred through } \\
\text { the individual's } \\
\text { perception }\end{array}$ & & $\begin{array}{l}\text { Lived experience } \\
\text { Could potentially } \\
\text { throw light on the } \\
\text { dynamics of }\end{array}$ \\
& & potential \\
& & & contradictions \\
\hline
\end{tabular}




\section{Research design and method}

This phenomenological study explored Greek female consumers' experiences with their meaningful possessions, products, and consumption activities in relation to desired and undesired selves. Because gender, as a major social category, is likely to influence self-concepts and consumption experiences, only women's consumption experiences were the focus for this study in order to reduce the complexity of examining both women's and men's consumption experiences across age groups. Convenience and snowball sampling was used to recruit 30 participants, 10 from each age span: $18-33,34-49$, and 50-65. For the purposes of this paper, we draw on the stories of 14 informants that reflect the findings of the whole data set. Their personal characteristics are summarised in Table 2 .

Phenomenological interviewing (Colaizzi, 1978; Kvale, 1983; Thompson et al., $1989,1990)$ was used to elicit full descriptions of experiences. The phenomenological interview is semi-structured. The respondents largely drive the conversation. The interviewer employs short descriptive questions and specifically avoids 'why' questions. Respondents were informed that the study's purpose was to obtain insights into their experiences with their meaningful possessions, products, and consumption activities. They were also told that the interview would be audiotaped, and anonymity was assured. To stimulate discussion about themselves, their lives, and consumption, informants were invited to 'Tell the story' about their meaningful possessions, products, and/or consumption activities.

Interviews were transcribed and a phenomenological-hermeneutical analysis (Thompson et al., 1989, 1990) using a back and forth, part-to-whole interpretation

Table 2 Informants' personal characteristics.

\begin{tabular}{|c|c|c|c|c|c|}
\hline $\begin{array}{l}\text { Age } \\
\text { span }\end{array}$ & Nickname & Age & $\begin{array}{l}\text { Marital } \\
\text { status }\end{array}$ & Occupation & $\begin{array}{l}\text { Most important possessions/ } \\
\text { products/consumption activities }\end{array}$ \\
\hline \multirow[t]{5}{*}{$18-33$} & Victoria & 27 & Engaged & $\begin{array}{l}\text { Architect } \\
\text { assistant }\end{array}$ & Clothes, laptop, studies, cosmetics \\
\hline & Elena & 28 & Engaged & Architect & Laptop, clothes, tennis, broach \\
\hline & Sofia & 29 & Married & Unemployed & Clothes, furniture, tutorials, photos \\
\hline & Nancy & 31 & Single & Clerical & Car, mobile, clothes, trips \\
\hline & Fofika & 33 & Divorced & $\begin{array}{l}\text { Middle-level } \\
\text { manager }\end{array}$ & Mobile, car, laptop, house, studies \\
\hline \multirow[t]{5}{*}{$34-49$} & Nena & 36 & Single & Tour guide & Ring, heirloom, house, car \\
\hline & Patca & 38 & Single & Pharmacist & Music CDs, (self)gifts, books, theatre \\
\hline & Julia & 43 & Married & $\begin{array}{l}\text { White-collar } \\
\text { manager }\end{array}$ & Ring gift, organic products, house \\
\hline & Maria & 46 & Married & Clerical & $\begin{array}{l}\text { House, necklace, perfume, clothes, } \\
\text { cafés }\end{array}$ \\
\hline & Mina & 48 & Married & Clerical & $\begin{array}{l}\text { Cosmetics, clothes, education, } \\
\text { furniture }\end{array}$ \\
\hline \multirow[t]{4}{*}{$50-65$} & Andy & 53 & Married & $\begin{array}{l}\text { TV/radio } \\
\text { producer }\end{array}$ & Trips, piano, house, son's education \\
\hline & Nana & 57 & Separated & Housewife & Music CDs, paintings, clothes, bars \\
\hline & Joanna & 64 & Widow & Retired & Houses, lamp, furniture, books, trips \\
\hline & Rea & 65 & Single & Retired & Diet, pet, flowers, gifts, mobile \\
\hline
\end{tabular}


mode was applied to the data in order to generate theory building around the desired and undesired selves and their interrelationship in consumption.

\section{Findings and discussion}

The findings suggest that the desired and undesired self coexist for consumers in the Greek context, colouring their consumption experiences. Table 3 presents briefly the themes around which consumers' predominant desired and undesired selves revolved. Table 4 provides a few examples of how respondents' desired and undesired selves revolved around these themes, followed by a brief discussion of these themes in regards to the context in which they emerged. Then the focus turns to identifying and conceptualising two patterns that capture the dynamic interrelationship between desired and undesired selves in consumption.

\section{Thematic dimensions of desired and undesired selves}

Our participants' strong affiliation, security, and control needs are encouraged by the current difficult and uncertain economic climate, with factors such as high unemployment rates and the state's poor levels of support and protection for both young and elderly citizens in Greece (Eurostat, 2002). Young and elderly people in Greece and in other Mediterranean countries rely heavily on their nuclear families, in contrast to people in Scandinavian countries who are strongly supported by the state (Eurostat, 2002). Indeed, our respondents sought strong interpersonal ties with their

Table 3 Thematic dimensions of desired and undesired selves.

\begin{tabular}{|c|c|c|}
\hline Themes & Desired selves & Undesired selves \\
\hline Affiliation & $\begin{array}{l}\text { Feelings of belonging, being } \\
\text { accepted, and caring for others }\end{array}$ & $\begin{array}{l}\text { Feelings of being excluded, rejected, } \\
\text { alone, and not caring for others }\end{array}$ \\
\hline $\begin{array}{l}\text { Standing } \\
\text { out }\end{array}$ & $\begin{array}{l}\text { Feeling respected and proud, } \\
\text { standing out positively }\end{array}$ & $\begin{array}{l}\text { Feeling disrespected and ashamed, } \\
\text { standing out negatively }\end{array}$ \\
\hline Security & Feeling safe and secure & Feeling unsafe and insecure \\
\hline Control & Being in control & Not being in control \\
\hline Pleasure & Experiencing pleasure/enjoyment & Experiencing displeasure/pain \\
\hline
\end{tabular}

Table 4 Mapping themes across desired and undesired selves.

\begin{tabular}{|c|c|c|}
\hline Themes & Desired selves & Undesired selves \\
\hline Affiliation & $\begin{array}{l}\text { Being loved, fitting in, caring } \\
\text { for others }\end{array}$ & $\begin{array}{l}\text { Unloved, alone, negligent mother/ } \\
\text { daughter }\end{array}$ \\
\hline $\begin{array}{l}\text { Standing } \\
\text { out }\end{array}$ & $\begin{array}{l}\text { Beautiful, successful, } \\
\text { sophisticated }\end{array}$ & $\begin{array}{l}\text { Unattractive, failed, snobbish, } \\
\text { deprived, miserly }\end{array}$ \\
\hline Security & Financially secure, healthy, safe & $\begin{array}{l}\text { Financially insecure, unhealthy, } \\
\text { ill, unsafe }\end{array}$ \\
\hline Control & Free, independent, powerful & Oppressed, dependent, weak \\
\hline Pleasure & Indulgent, enjoying, relaxed & Stressed, in displeasure \\
\hline
\end{tabular}


nuclear family. Moreover, our participants sought security and control in reaction to the environmental uncertainty that surrounds them; they were motivated to minimise financial uncertainty and risk in order to ensure that they achieved a degree of protection for and control over the future.

\section{Patterns of interrelationships between desired and undesired selves}

Two dynamic patterns of interrelationship between desired and undesired selves were conceptualised from this study. This part of the paper is structured as follows. First, in section 1 , we discuss pattern $\mathrm{A}$, then we identify different motivations in pattern $\mathrm{A}$, and subsequently we discuss two different emergent strategies linked to different motivations in pattern A. Next in section 2, we move on to pattern B, the relevant motivation, and the relevant consumers' strategies. Table 5 summarises the findings discussed further in sections 1 and 2.

\section{Pattern A: Dynamic of conflicting desired and undesired selves}

In the first pattern (A), consumers experience the dilemma of choosing between one pair of desired/undesired selves over another pair of desired/undesired selves (win-lose situations). Maria (46 years old), for example, experiences the dilemma of choosing between either 'being a caring mother but not enjoying herself' or 'enjoying herself but being a negligent mother', which are two opposite possible identities, each involving a desired and an undesired self (affiliation and pleasure themes). In this case, dilemmas and tensions are experienced, as described in earlier studies as life themes or

Table 5 Patterns of consumers' desired and undesired selves' interrelationships, consumers' motivation, and strategies.

\begin{tabular}{lcc}
\hline Patterns & Motivation & Strategies \\
\hline A: Conflicting desired and undesired selves & Approach a desired self & Choice strategy \\
Existential dilemmas; win-lose situations; & - Abandoning another & \\
$\begin{array}{l}\text { e.g. pursuing a desired self necessitates } \\
\text { acceptance of an undesired self }\end{array}$ & desired self and/or & \\
& Accepting one & \\
& undesired self & \\
& Avoid an undesired self & \\
& - accepting another & \\
& undesired self and/or & \\
& - abandoning one & \\
& desired self & \\
& Unclear framing around & Balance \\
& desired and undesired & strategy \\
& selves & Transition \\
& & strategy \\
B: Compatible desired and undesired & Approach a desired self & Straightforward \\
selves No dilemma; win-win situations; & and avoid an undesired & strategy \\
pursuing a desired self means avoiding an & self & \\
undesired self and vice versa & & \\
\hline
\end{tabular}


identity conflicts (e.g. Ahuvia, 2005; Fournier, 1998). Respondents with such conflicting desired and undesired selves experienced a sense of 'baffled' self (T. Miller, 2009) and often the need to compromise due to the dilemma of choosing between two possible and competing identities. Several dilemmas emerged from respondents' lifeworld descriptions such as 'enjoying myself or being a caring mother' (Maria, Andy), 'looking feminine or feeling comfortable' (Victoria), 'being healthy or indulging' (Rea).

Such existential dilemmas mirror the tensions between choosing an identity and the constraints in doing so (Shankar, Elliott, \& Fitchett, 2009). Moreover, such existential dilemmas were reflected in consumers' experiences with their important possessions, products, and consumption activities. The important object or activity in this case enables and activates both a desired and an undesired self. The consumer associates the special item or activity with both her desired self and undesired self, has both positive and negative memories about it, has mixed feelings about it, and has a 'love-hate' relationship with it.

Often respondents experiencing such dilemmas of choosing between one pair of conflicting desired/undesired selves over another were more motivated either to pursue one desired self or to avoid one undesired self. However, sometimes there was a less clear framing of consumers' decisions around their desired/undesired selves.

\section{Pursuing a desired self}

Often respondents pursued one desired self in preference to another; that is, they pursued one desired self and abandoned or neglected an alternative desired self. For example, Mina (48 years old) pursues her desired self of being 'a caring mother' rather than her other desired self of 'looking beautiful and young'. Therefore, she pays for her daughter's private education, which means that she can only afford to buy cosmetics that she considers cheap and about which she has mixed feelings. She feels that these cosmetics are not very effective in helping her to achieve her desired self of 'looking beautiful and young'. She says:

Cosmetics are important to look beautiful and young ... if I had financial comfort I would buy more expensive and therefore more effective cosmetics, but I consider my daughter's education as a priority now.

Respondents also discussed how pursuing a desired self often required the acceptance of an undesired self. Mina, for example, discussed how she provides private education for her daughter and thus pursues her desired self as 'a caring mother' and has at the same time to accept her 'financially pressured' undesired self.

\section{Avoiding an undesired self}

In other cases, respondents chose to avoid one undesired self but chose (accepted or reluctantly embraced, or compromised with) another undesired self, and/or abandoned/neglected one desired self.

Victoria (27 years old), for example, avoids her undesired self 'feeling uncomfortable and insecure', but at the cost of reluctantly embracing her other undesired self 'being shy and dressed conservatively' and abandoning the opportunity of achieving her desired self 'standing out as feminine' through her dressing choices. She enacts the 'shy' aspect of her self - which she considers unwanted but also impossible to avoid. Her description reveals the tension between her ability to create her identity through her choices and the constraints on her ability to do so (Shankar et al., 2009). She says: 
My clothes are conservative. I only like a cheap, feminine skirt, I bought not to wear, but because it is nice. I never wore it. I like feminine clothes that reveal parts of the body but as I am shy I always wear conservative clothes; feminine clothes attract others' attention and make me feel uncomfortable and insecure ... I admire women who dare to wear feminine clothes and stand out but I cannot.

\section{Choice strategy - Compromising and choosing one identity over another}

Respondents from pattern A (motivated either to approach a desired self or to avoid an undesired self) dealt with their dilemma of choosing between two possible identities, each of which involves simultaneously desirable and undesirable aspects of the self by making a compromising choice. They gave up what they saw as some of the attractive features of one identity and chose the other identity. Feelings of compromise and pressure were pre-eminent and reflected in consumers' love-hate relationship with the object or activity that mediated the choice.

The choice between two competing identities was often guided by a sense of the inability to pursue, cope with, or abandon one of the identities. For example, Victoria's choice of 'feeling comfortable and secure but not standing out as feminine' with her dress choices is based on her sense of inability to pursue and cope with 'standing out as feminine but feeling uncomfortable and insecure' (see also Table 6).

Nena (36 years old) chose to avoid her undesired 'oppressed' self (control theme) at the cost of abandoning her desired 'married woman' self (affiliation theme). She has mixed feelings about her ring from her broken engagement that symbolises her choice. She said: (see also Table 6)

The ring from my broken engagement is important to me. I haven't enjoyed it ... We broke up soon after the engagement. I kept this ring but I don't wear it ... The relationship became unfair for me. I was only giving. He did not want to give things back ... I was getting oppressed ... I want another engagement ring.

When faced with two conflicting desired/undesired selves, respondents often chose one identity over another because they considered the chosen identity to be more important than the abandoned identity. Maria, for example, when she became a mother for the first time, considered her desired 'caring mother' self as more important than her desired 'enjoying' self, and stopped engaging in self-grooming and entertainment activities and devoted all her free time to her child.

Moreover, a sense of obligation (or ought self) often guided the choice between two identities. Andy, for example, chose to pursue the desired self of being 'a caring mother' and therefore abandoned the opportunity to achieve her other desired self of 'enjoying' herself because she could not engage in her favourite activity of travelling. She feels she ought to make this choice and says:

I miss trips and entertainment ... I cannot do what I want because I have to stand by my son who is going to school. He needs to know that we are close to him and here for him. All our goals are on our son to study and succeed. We pay a lot for his education. We don't exist; he exists. When he is over 18 years old and starts working in parallel to his studies, we may start to exist again. (See also Table 6.)

These respondents, who followed this compromise strategy, were often trying to adapt to or prepare for a new private transition. Nena, for example, faced the 


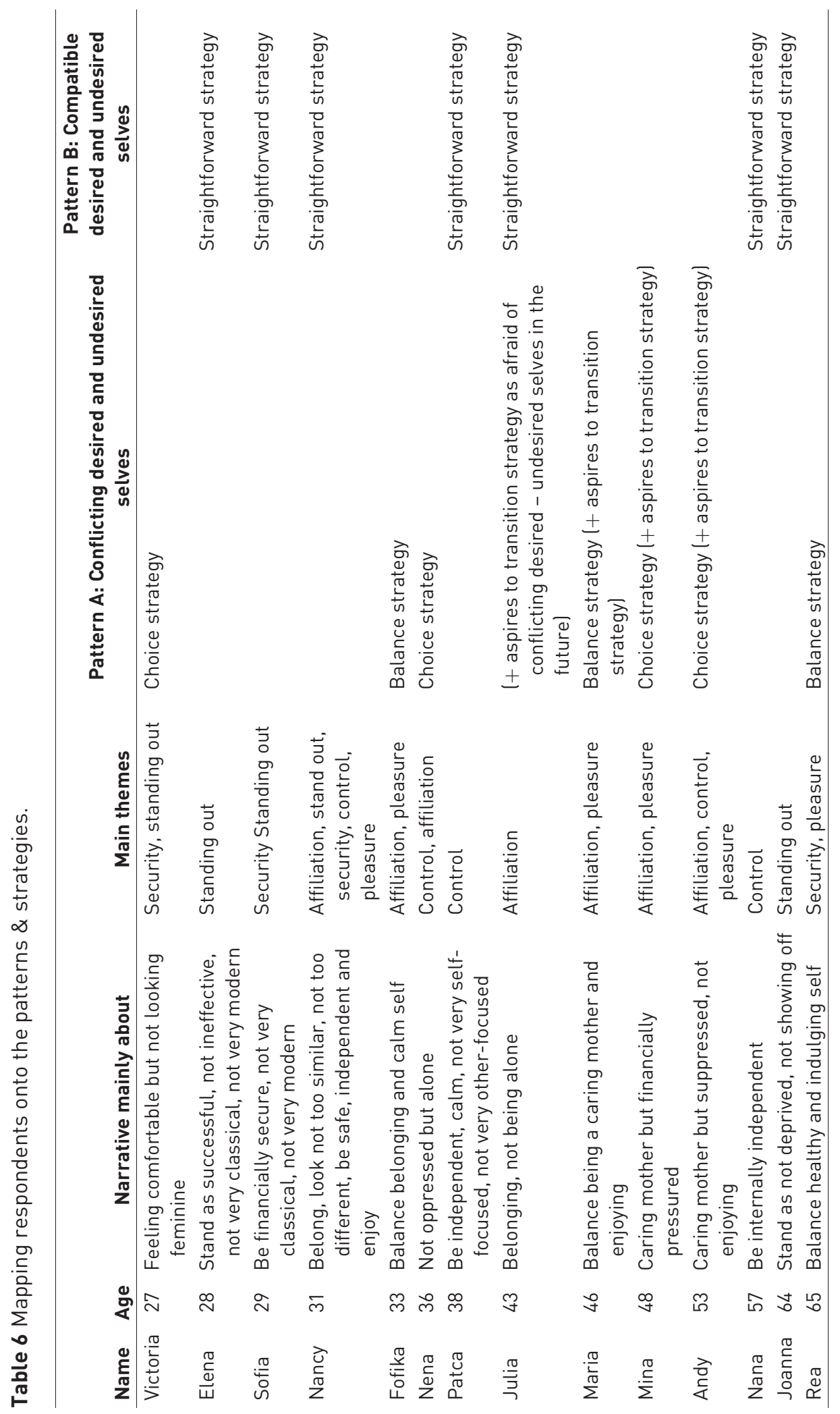


transition of getting married; Maria had faced the transition of motherhood; Andy was anticipating the transition to the state of being an empty nester.

\section{Less clear framing around desired/undesired selves}

In some cases, respondents experiencing identity dilemmas (pattern A) expressed less clear framing in regards to their desired and undesired selves and consumption. Fofika (33 years old), for example, has mixed feelings for her mobile phone, as it enables both her desired self 'being close to loved ones' (affiliation theme) and her undesired self 'pressured and tensed' (pleasure theme). Therefore, she regulates its use. She says:

My mobile is important as it gets me closer to my friends and family ... but it often makes me sad ... I cannot stand it. It pressures me because I receive family tension through it ... therefore I often keep it switched off.

Rea (65 years old) discussed the tension between two possible identities, that is, 'being healthy but not indulging' and 'indulging but not being healthy' (security and pleasure themes). Each of these identities involves both a desired and an undesired self. Rea tries to reconcile the tension between these two competing possible identities by watching her diet.

\section{Balance strategy: Compromising and pursuing the golden mean of two identities}

Respondents from the first pattern (such as Fofika, Maria, and Rea) with no clear framing around desired and undesired selves dealt with the dilemma of choosing between two identities (where each identity had both desirable and undesirable aspects) in a different way. They gave up what they saw as some of the attractive features of each identity in order to achieve a middle ground between the two identities. For example, Fofika pursues the compromise or golden mean between 'being close to loved ones but experiencing family tension' and being 'calm but lonely' by making limited use of her mobile about which she has mixed feelings. Maria, after giving birth to her second child, started pursuing the golden compromise or mean between being a caring mother and enjoying herself. At times, she enjoys self-grooming activities and going out with friends, feeling, however, she neglects her children; and at other times, she takes care of her children, doing household tasks, but she feels she is not enjoying herself. Therefore, she experiences feelings of compromise and has a love-hate relationship with her house. This is in line with Thompson's (1996) findings on working mothers' efforts to balance their inner conflicts between self-indulgence and caring for others.

It can be inferred that respondents are trying to achieve a compromise between two identities because both identities are equally important and/or desirable. Moreover, the choice of this balancing strategy might be attributed to a sense of obligation: an ought self. For example, Maria tries to achieve a balance between being a caring mother and enjoying herself because she feels she ought to be youthful for her son, and she feels she achieves that by enjoying herself. She says:

I used to stay in doing household tasks, not going out with friends to entertain in order to take care of my daughter. I was 37 years old when my son was born ... I had to stop being like before and renew myself as if I wouldn't, people would later think I'm my son's grandmother not his mother. [.. . Everybody says l've changed. I have a young son and I have to be young too and enjoy. The opposite shouldn't take place. 
Respondents who follow this balancing strategy tend to have relative stability in their lives, rather than being faced with transitions.

Overall, respondents in pattern A (whether following a choice or a balance strategy) experienced constraints in their identity choices associated with feelings of compromise and pressure. This tension between identity choices and identity constraints (Shankar et al., 2009) was mirrored in their consumption experiences.

\section{Pattern B: Dynamic of compatible desired and undesired selves}

The second dynamic pattern (B) of the interrelationship between the desired and undesired selves involves the enabling of the desired self and the deactivating of the undesired self via consumption (win-win situations). In this case, consumers' pursuit of their desired self meant they succeeded in avoiding an undesired self and vice versa. No dilemmas, existential tensions, or compromising feelings were experienced. Rather, possessions, products, and consumption activities were valued because they enabled a consumer's desired selves and deactivated a consumer's undesired selves. The consumer has only positive memories from and positive feelings about such objects and activities. Patca and Nana, for example (38 and 57 years old respectively), valued art-related items (music CDs and books) for enabling desired selves such as being 'calm' and 'internally independent' and for preventing or offering relief from the undesired self of feeling 'upset' and 'dependent'.

Joanna (64 years old) illustrates that the opposite of an undesired self is not necessarily the desired/ideal self. Joanna appears not to want to be associated with two equally undesirable, yet completely opposite, self-concepts. One undesired self-concept consists of being perceived as poor, while the other undesired self consists of looking too wealthy:

On the one side is a person who has everything, shows off, and this is obvious to others. On the other side is a person who has nothing, is miserly, and this is obvious to others too. I don't want to be on either side... I don't show off by over consuming but I am not miserly either in under consuming ... I don't want to belong or to be considered on either side.

Several respondents from pattern B revealed that they were sometimes avoiding two completely opposite undesired selves whilst simultaneously pursuing a desired self in the middle of the two opposite extremes represented by two different undesired selves. For example:

- Avoid being either very modern or very classical, but pursue a desired self in the middle (e.g. with furniture, clothing choices; Elena, Sofia)

- Avoid being too similar to others and also very different from others le.g. with clothing choices; Nancyl

- Avoid being very self-focused, and also avoid being very other-focused at the same time (e.g. balancing self-gifts and gifts to others; Patca).

This view of the undesired self at the two extreme ends of a spectrum of the self, with the desired self in the middle (and equipoise point) of an axis, potentially provides an interesting complement to Sullivan's (1953) theorisation that the desired self is more vague and abstract than the undesired self. It also links with Ogilvie's (1987) statement that the undesired self is a more concrete and unshakeable standard against which one judges one's present level of well-being than the desired self. This view is also in line 
with the concept of the ideal of personhood as a centralised equilibrium-preserving structure (Erikson, 1959; Geertz, 1973, 1979; Greenwald, 1980, in Sampson, 1985).

Respondents from pattern $\mathrm{B}$ did not experience as problematic or difficult the pursuit of a desired self that sits at the equipoise or balancing point between two completely opposite undesired selves. In contrast, respondents from pattern A in pursuit of equilibrium between two competing identities (balance strategy) did experience the balancing act as difficult and problematic, and they expressed feelings of compromise and pressure.

\section{Straightforward strategy}

Respondents with compatible desired and undesired selves (pattern B, e.g. Elena, Sofia, Nancy, Patca, Julia, Nana, and Joanna) approach desired selves and avoid undesired selves via consumption in a straightforward way. They do not experience tensions or compromising feelings and have only positive feelings and memories about the possessions and activities that enabled their desired selves and deactivated their undesired selves (see also Table 6).

\section{Transition aspiring strategy: Solving the dilemma - Transition from pattern A to $B$}

In some cases, respondents aspired to solve the dilemma of choosing between different identities, each of which involved both a desired and an undesired self. The solution would enable the desired aspects and deactivate the undesired aspects of both identities, solving the dilemma. Thus desired and undesired selves would cease to be in conflict (pattern A) and become compatible (pattern B). Compromising feelings would be overcome (see also Table 6).

Maria, for example, aspires to solve her dilemma of choosing between caring for her loved ones and enjoying herself by taking early retirement. By doing so, she hopes to achieve both of her desired selves 'enjoying' and 'taking good care of her family', and to avoid her undesired selves 'negligent mother' and 'not enjoying herself'.

Nena (aged 36) is hoping to establish a fair and harmonious personal relationship that will solve her dilemma of having to choose between affiliation and control.

Mina who chooses the 'caring mother but financially pressured' pair of conflicting desired and undesired selves (she is paying for her daughter's private education) is hoping that her husband will find a better-paid job.

Andy is looking forward to her son becoming financially independent, hoping that this transition will solve the dilemma of choosing between caring for her son and enjoying herself.

Julia (pattern B at the time of the interview) feels that, in the future, retirement will stimulate not only her desired self, that is, 'more relaxed' but also her undesired 'lonely' self (pattern A and pleasure and affiliation themes). She intends to have a country house built on an island where her best friends are living. This way she hopes she will enable both her desired selves, 'relaxed' and 'belonging', and will prevent realisation of her undesired selves, 'lonely' and 'not relaxed' (avoid pattern A).

This strategy emerged as an aspirational strategy in our study. Respondents aspired to solve dilemmas in the future due to opportunities that they anticipated would be created by a transition to the next life stage (e.g. retirement, empty nest) or by a desired life change (e.g. find a partner) or consumption (e.g. country house). 
Overall, respondents followed different strategies based on:

- The importance they placed on their different desired and undesired selves

- Their sense of obligation or ought self

- Their feelings towards their sense of identity constraints

- Their transitional or stable life state.

Table 6 maps respondents onto the two patterns and four strategies discussed above.

\section{Conceptualisation}

Figure 1 shows the framework of how the interplay between desired and undesired selves is mediated via consumption emerged from the analysis and depicts the two dynamic interrelationship patterns ( $\mathrm{A}$ and $\mathrm{B}$ ) between respondents' desired and undesired selves, and the variety of strategies (I-IV) that respondents used in order to deal with these patterned interrelationships. In line with the phenomenological perspective, this framework follows the viewpoint of the respective respondents.

\section{Comparison with a US study (Ahuvia, 2005)}

How do our findings align with earlier US work and theory building (Ahuvia, 2005)? The four strategies that our respondents in Greece used in order to handle the dynamics between their desired and undesired selves (patterns A and B) were in some ways in line with three strategies that US respondents had followed in order to deal with their identity conflicts and to create a coherent self-narrative (Ahuvia, 2005). (Note that the pattern A in our study, which identified the role of identity conflicts, i.e. conflicting desired and undesired selves, aligns with Ahuvia's study.) Table 7 summarises the differences and similarities in the strategies consumers followed, comparing Ahuvia's with our findings.

Of particular interest here is the third strategy identified in Ahuvia (2005). This is the 'synthesising' strategy where the consumer creates a synthesis of opposing identities (getting the best of both worlds). In the synthesising strategy, US consumers created a sense of self-coherence and overcame compromising feelings via consumption without really solving their identity conflicts. Their identity dilemmas continued to exist. We did not find this strategy among our Greek respondents. Rather, our Greek participants aspired to solve their identity dilemmas and conflicts via life transitions, life changes, and consumption in order to overcome compromising feelings and to create a coherent sense of self using the 'transition strategy' (to which they aspired).

This is an important emergent difference between Ahuvia's US respondents and our Greek respondents. While our Greek respondents aspired to solve their identity conflicts, the US respondents accepted their identity conflicts. While our Greek respondents needed to solve their identity conflicts in order to overcome their feelings of compromise and pressure, and also in order to experience a sense of selfcoherence, the US respondents were able to overcome compromising feelings and to experience a sense of self-coherence without solving their identity conflicts. This possibly suggests that our respondents in Greece felt more uncomfortable than 
Figure 1 Interplay of desired and undesired selves mediated via consumption.

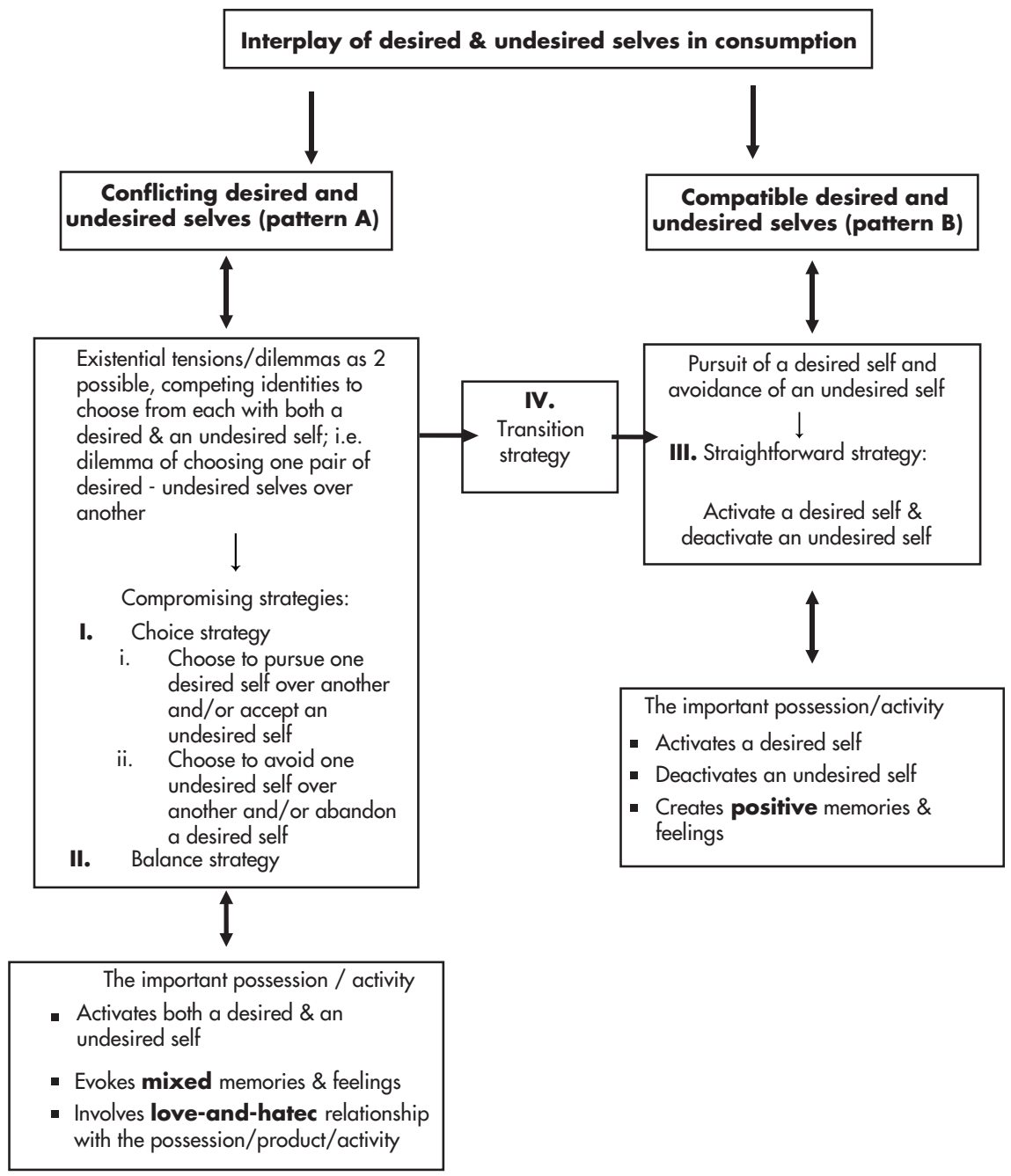

respondents in the United States with identity conflicts. Greek consumers seemed to have a sense of 'baffled' self (T. Miller, 2009) when their identity conflicts had not been solved.

\section{Cross-cultural issues}

So, are consumers becoming increasingly homogenised in a global consumer culture? Our study reports similarities as well as differences in symbolic consumption between Greece and the United States.

The view that important items are connected to the self by both expressing and transforming the self into some new desired form was supported by Ahuvia's (2005) US-based study and is also supported by our findings for Greek consumers. Moreover, just like US respondents (Ahuvia, 2005), our respondents in Greece also have a great 
Table 7 Consumers' strategies.

\begin{tabular}{|c|c|c|}
\hline $\begin{array}{l}\text { Strategies in Ahuvia (2005) - } \\
\text { US respondents }\end{array}$ & $\begin{array}{l}\text { Strategies in our study } \\
\text { - Greek respondents }\end{array}$ & Comments \\
\hline Demarcating strategy: & 1. Choice strategy: & \multirow{5}{*}{$\begin{array}{l}\text { Ahuvia's interpretation of } \\
\text { demarcating points to two } \\
\text { potentially different } \\
\text { strategies las found in our } \\
\text { datal and so he would seem to } \\
\text { be offering two potentially } \\
\text { inconsistent views of the } \\
\text { demarcating strategy }\end{array}$} \\
\hline $\begin{array}{l}\text { The consumer chooses one } \\
\text { identity and rejects another }\end{array}$ & $\begin{array}{l}\text { In line with the first } \\
\text { view of Ahuvia's } \\
\text { 'demarcating } \\
\text { strategy' }\end{array}$ & \\
\hline Potentially inconsistent views: & & \\
\hline 1. strategy used by consumers & $\begin{array}{l}\text { 2. Straightforward } \\
\text { strategy: }\end{array}$ & \\
\hline $\begin{array}{l}\text { 2. strategy used by consumers } \\
\text { who 'strongly prefer one } \\
\text { identity over another' (and } \\
\text { who thus experience no } \\
\text { identity conflict) (p. 181) }\end{array}$ & $\begin{array}{l}\text { In line with Ahuvia's } \\
\text { second description of } \\
\text { the 'demarcating } \\
\text { strategy' }\end{array}$ & \\
\hline $\begin{array}{l}\text { Compromising strategy: } \\
\text { Suggested, but not } \\
\text { empirically supported, in } \\
\text { Ahuvia's study }\end{array}$ & 3. Balance strategy & $\begin{array}{l}\text { Our Greek study provides } \\
\text { empirical support for this } \\
\text { strategy }\end{array}$ \\
\hline Synthesising strategy & - & $\begin{array}{l}\text { For the US respondents, } \\
\text { identity conflicts are not } \\
\text { solved but compromising } \\
\text { feelings are overcome to } \\
\text { create a self-coherence } \\
\text { sense. There was no } \\
\text { empirical evidence for this } \\
\text { strategy from this study of } \\
\text { Greek consumers. }\end{array}$ \\
\hline - & 4. Transition strategy & $\begin{array}{l}\text { Aspiring to solve identity } \\
\text { conflicts in order to overcome } \\
\text { compromising feelings and } \\
\text { create a self-coherence } \\
\text { sense }\end{array}$ \\
\hline
\end{tabular}

deal of choice about who they want to be, and experience identity conflicts (illustrated by pattern A of conflicting desired and undesired selves) that colour their consumption experiences. Our findings suggest that contemporary conditions in Greece resemble those in the United States in that they make the establishment of a coherent sense of self difficult. Just like the US respondents (Ahuvia, 2005), our Greek respondents can construct their identity from an abundance of identities and did not experience the difficulties in constructing a coherent sense of self as the liberation from an oppressive ideal of a unified self (Firat \& Venkatesh, 1995) or with a sense of an 'empty' self (Cushman, 1990).

However, our Greek respondents seemed to feel more uncomfortable than the US respondents with the difficulties they faced in constructing a coherent sense of self and with their identity conflicts. Therefore, our Greek respondents seem to deal with their identity conflicts in a different way from US participants (Ahuvia, 2005), often following different strategies. Our study identifies less coherence in the concept of 
self and more ambivalence in the emotions surrounding consumption than Ahuvia's study. Ahuvia's US respondents managed to create a sense of self-coherence without solving their identity conflicts by combining (synthesising) conflicting standards through consumption of loved objects. Our informants aspired to solve their identity conflicts via life transitions, life changes, and consumption in order to create a sense of self-coherence. For our Greek respondents, conflicting standards are not combined (synthesised) through consumption (as for US respondents in Ahuvia, 2005; Holt \& Thompson, 2004), but rather create ambivalent/mixed emotions in consumption and the sense of a 'baffled' self (T. Miller, 2009). Consumers in our study tried to achieve a compromising balance between opposing identity positions (as consumers in Thompson, 1996) or to compromise with one identity position while often aspiring to overcome the identity conflict in the future.

\section{Conclusion}

This study sought to conceptualise the interrelationship between desired and undesired selves and to highlight how the interplay between different selves was significant in the consumption experiences of Greek women. The present interpretation focuses on the experiences of women situated in a particular context, and are supported by the transcriptions. However, we do not claim to have developed an exhaustive account. Different insights could emerge across different settings. The interplay between the desired and undesired selves of male consumers, for instance, would represent another important avenue to be explored by future research.

As discussed in the previous section, our study adds to existing consumer research, which has largely concentrated on the United States, providing a more nuanced understanding of how symbolic consumption works within global consumer culture. Consumers in this study did not experience fragmented multiple selves (Firat \& Venkatesh, 1995), an 'empty-self' (Cushman, 1990), or a coherent self created out of synthesis of opposite identities (Ahuvia, 2005). Rather, they experienced the desire for a coherent self that often left them with a sense of baffled self (T. Miller, 2009) when coherence was not attained. Informants in this study aspired to solve their identity conflicts via life transitions, life changes, and consumption in order to create a sense of self-coherence. And this study identified more ambivalence in the emotions surrounding consumption than previous work (Ahuvia, 2005; Cushman, 1990; Firat \& Venkatesh, 1995).

We extend theory on the desired/undesired self by mapping the desired and undesired self in terms of thematic dimensions, conceptualising two interrelationship patterns (A and $\mathrm{B}$ ) between desired and undesired selves, and examining the impact of these interrelationships on four consumer strategies. The first pattern (A) of 'conflicting desired and undesired selves' identified in this study integrates two major developments in consumer research on identity: (1) desired and undesired self-concept (Banister \& Hogg, 2001, 2003; Freitas et al., 1997; Patrick \& MacInnis, 2002; Wilk, 1997); and (2) identity conflicts/tensions (e.g. Ahuvia, 2005; Fournier, 1998). We also identify consumers' mixed feelings for and often their love-hate relationship with their important possessions, products, and consumption activities. Finally, we extend Ahuvia's theory on the strategies consumers use to handle identity issues, and we identify different conditions under which consumers follow different strategies. 
The findings can offer additional insights of value to marketing managers in terms of marketing segmentation, targeting, and positioning techniques. Marketing strategists need to recognise the desired and undesired selves' associations with product and service choices and anti-choices, understand the desired and undesired selves' themes and interrelationships in consumption, and exploit this understanding in the development of communication and channel strategies for the positioning and branding of their goods and services. Finally, as desired and undesired selves often relate to social roles (e.g. mother), the findings can also offer insights to role theory and more specifically to role conflict, as well as to role-related consumption. From the perspective of symbolic interactionism, the findings can throw light on how consumers as social actors pursue personal coherence across different settings (Goffman, 1959), and choose and use products as social stimuli to perform roles and to define the self (Solomon, 1983).

\section{References}

Ahuvia, A.C. (2005). Beyond the extended self: Loved objects and consumers' identity narratives. Journal of Consumer Research, 32, 171-184.

Arnould, E.J., \& Thompson, C.J. (2005). Consumer Culture Theory (CCT): Twenty years of research. Journal of Consumer Research, 31(4), 868.

Banister, E.N., \& Hogg, M.K. (2001). Mapping the negative self: From 'so not me' ... to 'just not me. Advances in Consumer Research, 28, 242-248.

Banister, E.N., \& Hogg, M.K. (2003). Possible selves: Identifying dimensions for exploring the dialectic between positive and negative selves in consumer behaviour. Advances in Consumer Research, 30, 149.

Bauman, Z. (1991). Modernity and ambivalence. Cambridge, England: Polity Press.

Belk, R.W. (1988). Possessions and the extended self. Journal of Consumer Research, 15(2), 139-168.

Belk, R.W. (1989). Extended self and extending paradigmatic perspective. Journal of Consumer Research, 16, 129-132.

Borgerson, J. (2005). Materiality, agency, and the constitution of consuming subjects: Insights for consumer research. Advances in Consumer Research, 32, 439-443.

Cherrier, H., \& Murray, J.F. (2007). Reflexive dispossession and the self: Constructing a processual theory of identity. Consumption, Markets and Culture, 10(1), 1-29.

Colaizzi, P.F. (1978). Psychological research as the phenomenologist views it. In R.W. Valle \& J. King (Eds.), Existential-phenomenological alternatives for psychology. New York: Oxford University Press.

Crotty, M. (2003). The foundations of social research, meaning and perspective in the research process. London: Sage.

Csíkszentmihályi, M., \& Rochberg-Halton, E. (1981). The meaning of things: Domestic symbols and the self. Cambridge, England: Cambridge University Press.

Cushman, P. (1990). Why the self is empty: Toward a historically situated psychology. American Psychologist, 45(5), 599-611.

Dittmar, H. (1991). Meanings of material possessions as reflections of identity: Gender and social material position in society. To have possessions: A handbook of ownership and property [Special issue]. Journal of Social Behaviour and Personality, 6, 165-186.

Elliott, R., \& Wattanasuwan, K. (1998). Consumption and the symbolic project of the self. In B. Englis \& A. Olofsson (Eds.), European Advances in Consumer Research (pp. 17-20). Provo, UT: Association for Consumer Research.

Erikson, E.H. (1959). Identity and the life cycle. New York: International Universities Press.

Eurostat (2002). The life of women and men in Europe. Luxembourg: European Communities. 
Firat, F.A., \& Venkatesh, A. (1995). Liberatory postmodernism and the reenchantment of consumption. Journal of Consumer Research, 22(3), 239-267.

Fournier, S. (1998). Consumers and their brands: Developing relationship theory in consumer research. Journal of Consumer Research, 24(4), 343.

Freitas, A., Davis, C.H., \& Kim, J.W. (1997). Appearance management as border construction: Least favorite clothing, group distancing and identity ... Not! Sociological Inquiry, 67(3), 323-335.

Gergen, K.J. (1991). The saturated self: Dilemmas of identity in contemporary life. New York: Basic Books.

Geertz, C. (1979). From the native's point of view: On the nature of anthropological understanding. In P. Rabinow \& W.M. Sullivan (Eds.), Interpretive social science (pp. 225-241). Berkeley: University of California Press.

Geertz, C. (1973). The interpretation of cultures. New York: Basic Books.

Greenwald, A.G. (1980). The totalitarian ego: Fabrication and revision of personal history. American Psychologist, 35, 603-618.

Giddens, A. (1991). Modernity and self-identity. Cambridge, England: Polity Press.

Goffman, E. (1959). The presentation of self in everyday life. New York: Anchor.

Gould, S.J., \& Lerman, D.B. (1998). 'Postmodern' versus ‘long-standing' cultural narratives in consumer behavior: An empirical study of NetGirl online. European Journal of Marketing, 32(7/8), 644-654.

Gubrium, J.F., \& Holstein, J.A. (1998). Narrative practice and the coherence of personal stories. Sociological Quarterly, 39(1), 163-187.

Heidegger, M. (1962). Being and time. New York: Harper \& Row.

Holt, D.B. (2002). Why do brands cause trouble? A dialectical theory of consumer culture and branding. Journal of Consumer Research, 29(1), 70.

Holt, D.B., \& Thompson, C.J. (2004). Man-of-action heroes: The pursuit of heroic masculinity in everyday consumption. Journal of Consumer Research, 31, 425-440.

Kleine, S.S., Kleine, R.E., \& Allen, C.T. (1995). How is a possession 'me' or 'not me'? Characterizing types and an antecedent of material possession attachment. Journal of Consumer Research, 22(3), 327-343.

Kvale, S. (1983). The qualitative research interview: A phenomenological \& hermeneutical mode of understanding. Journal of Phenomenological Psychology, 14, 17.

Levy, S.J. (1959). Symbols for sale. Harvard Business Review, 37(4), 117.

Markus, H., \& Nurius, P. (1986). Possible selves. American Psychologist, 41(9), 954.

McAdams, D.P. (2006). The problem of narrative coherence. Journal of Constructivist Psychology, 19(2), 109-125.

Miller, D. (1987). Material culture and mass consumption. Oxford, England: Berg.

Miller, T. (2009, May). Engaging with the maternal: Tentative mothering acts and the props of performance. Paper presented in the Motherhood, Consumption and Transition, 2nd seminar, Lancaster University.

Murray, J.B. (2002). The politics of consumption: A re-inquiry on Thompson and Haytko's (1997) 'Speaking of Fashion'. Journal of Consumer Research, 29, 427.

Myers, E. (1985). Phenomenological analysis of the importance of special possessions. Advances in Consumer Research, 12, 560-565.

Ogilvie, D.M. (1987). The undesired self: A neglected variable in personality research. Journal of Personality and Social Psychology, 52(2), 379-385.

Patrick, V.M., \& MacInnis, D.J. (2002). Approaching what we hope for and avoiding what we fear: The role of possible selves in consumer behaviour. Advances in Consumer Research, 29, 270-276.

Raggatt, P. (2006). Multiplicity and conflict in the dialogical self: A life narrative approach. In D.P. McAdams, R. Josselson, \& A. Lieblich (Eds.), Identity and story: Creating self in narrative. Washington, DC: American Psychological Association Books.

Reed, A. (2002). Social identity as a useful perspective for self-concept based consumer research. Psychology and Marketing, 19(3), 235. 
Richins, M.L. (1994a). Valuing things: The public and private meanings of possession. Journal of Consumer Research, 21, 504-521.

Richins, M.L. (1994b). Special possessions and the expression of material values. Journal of Consumer Research, 21, 522-533.

Sampson, E.E. (1985). The decentralization of identity - Toward a revised concept of personal and social order. American Psychologist, 40(11), 1203-1211.

Sartre, J.P. (1943). Being and Nothingness: An Essay on Phenomenological Ontology, Trans. H. Barnes, London: Routledge.

Schau, H.J., \& Gilly M.C. (2003). We are what we post? Self-presentation in personal web space. Journal of Consumer Research, 30, 385-404.

Schouten, J. (1991). Selves in transition: Symbolic consumption in personal rites of passage and identity reconstruction. Journal of Consumer Research, 17, 412.

Schultz, S.E., Kleine, R.E., III, \& Kernan, J.B. (1989). 'These are a few of my favorite things': Toward an explication of attachment as a consumer behavior construct. In T. Srull (Ed.), Advances in Consumer Research (Vol. 16, pp. 359-366). Provo, UT: Association for Consumer Research.

Shankar, A., Elliott, R., \& Fitchett, J.A. (2009). Identity, consumption and narratives of socialization. Marketing Theory, 9(1), 75-94.

Shankar, A., Elliott, R., \& Goulding, C. (2001). Understanding consumption: Contributions from a narrative perspective. Journal of Marketing Management, 17(3-4), pp. 420-453.

Solomon, M.R. (1983). The role of products as social stimuli: A symbolic interactionism perspective. Journal of Consumer Research, 10, 319-329.

Sullivan, H.S. (1953). The interpersonal theory of psychiatry. New York: Norton.

Taylor, C. (1989). Sources of the self: The making of modern identity. Cambridge, England: Cambridge University Press.

Thompson, C.J. (1996). Caring consumers: Gendered consumption meanings and the juggling lifestyle. Journal of Consumer Research, 22(4), 388-407.

Thompson, C.J. (1997). Interpreting consumers: A hermeneutical framework for deriving marketing insights from the texts of consumers' consumption stories. Journal of Marketing Research, 34, 438-455.

Thompson, C.J., \& Haytko, D.L. (1997). Speaking of fashion: Consumers' uses of fashion discourses and the appropriation of countervailing cultural meanings. Journal of Consumer Research, 24, 15.

Thompson, C.J., \& Hirschman, E.C. (1995). Understanding the socialized body: A poststructuralist analysis of consumers' self-conceptions, body images, and self-care practices. Journal of Consumer Research, 22(2), 139-153.

Thompson, C.J., Locander, W., \& Pollio, H. (1990). The lived meaning of free choice: An existential-phenomenological description of everyday consumer experiences of contemporary married women. Journal of Consumer Research, 17, 346.

Thompson, C.J., Pollio, H.R., \& Locander, W.B. (1989). Putting consumer experience back into consumer research: The philosophy and method of existential-phenomenology. Journal of Consumer Research, 16, 133-146.

Thompson, C.J., \& Tambyah, S.K. (1999). Trying to be cosmopolitan. Journal of Consumer Research, 26, 214-241.

Wallendorf, M., \& Arnould, E. (1988). My favorite things: A cross-cultural inquiry into object attachment, possessiveness and social linkage. Journal of Consumer Research, 14, 531-547.

Wilk, R.R (1997). A critique of desire: Distaste and dislike in consumer behavior. Consumption, Markets and Culture, 1(2), 175-196.

Wright, N.D., Claiborne, C.B., \& Sirgy, M.J. (1992). The effects of product symbolism on consumer self-concept. Advances in Consumer Research, 19, 311. 


\section{About the authors}

Katerina Karanika is lecturer in Marketing at the University of Exeter. She completed her PhD at Lancaster University. She studied Business Administration at University of Macedonia (Thessaloniki, Greece), followed by a M.Sc. in Marketing Management at Aston University. Then She worked as a qualitative marketing researcher in Synovate - Censydiam (International Consultant Marketing Research Company; Athens branch). Her research interests are around consumers' desires, distastes, identity projects and symbolic (anti-) consumption as well as around cultural aspects of identity and consumption. She has presented papers at a number of international conferences including Consumer Culture Theory Conference (CCT), European Marketing Academy $(E M A C)$ and European Advances in Consumer Research (EACR).

Corresponding author: Katerina Karanika, University of Exeter Business School, Streatham Court, Streatham Campus, University of Exeter, Exeter, EX4 4ST, Devon, UK.

T $\quad+44(0) 1392723458$

E K.Karanika@exeter.ac.uk

Margaret K. Hogg is professor of consumer research at Lancaster University in the UK. Before joining LUMS in 2004, she was reader in consumer behaviour at Manchester School of Management, UMIST. She read politics and modern history at Edinburgh University, followed by postgraduate studies in history at the Vrije Universiteit, Amsterdam, and then by an MA in Business Analysis at Lancaster University. She spent six years working in marketing with K Shoes, Kendal. She completed her part-time PhD at Manchester Business School in consumer behaviour and retailing, whilst lecturing at University College Salford. Her research interests are around the issues of identity, self, and consumption. Her work has appeared in refereed journals including the Journal of Advertising (in press), Journal of Business Research, Journal of Marketing Management, and the European Journal of Marketing. She has presented papers at a number of international conferences including European Marketing Academy (EMAC) and US and European meetings of the Association for Consumer Research (ACR), and AMA Marketing and Public Policy.

T +44 (0) 1524594149

Em.hogg@lancaster.ac.uk 